\title{
Flowering Dogwood Infections with Macrophomina phaseolina
}

\author{
Margaret T. Mmbaga ${ }^{1}$ and Lucas A. Mackasmiel \\ Department of Agricultural and Environmental Sciences, College of \\ Agriculture, Tennessee State University, 3500 John A Merritt Boulevard, \\ Nashville, TN 37209

\section{Frank A. Mrema} \\ Department of Research and Applied Sciences, Alcorn State University, \\ Lorman, MS 39096-7500
}

Additional index words. Cornus florida, root rots, stem canker, nursery crops, soilborne pathogens

\begin{abstract}
Macrophomina phaseolina was isolated from the crown region and roots of mature flowering dogwood (Cornus florida L.) trees in the landscape and nursery plantings. Although this pathogen has been reported in Cornus species, its occurrence and impact on $C$. florida has not been reported. Pathogenicity tests were conducted on dogwood seedlings, and all inoculated seedlings developed root necrotic lesions and no small lateral roots, whereas the non-inoculated control seedlings remained disease-free and developed numerous small roots. Seedlings inoculated with $M$. phaseolina exhibited numerous microsclerotia, but non-inoculated seedlings did not. In greenhouse experiments, plants inoculated on the stems near the soil line developed brown canker-like lesions and swellings around the inoculated area. These were not observed on noninoculated plants.
\end{abstract}

Macrophomina phaseolina is a welldocumented soilborne pathogenic fungus that causes root rot or charcoal rot, collar rot, and damping-off diseases in diverse plants. More than 500 plant species across $\approx 100$ genera that include food crops, ornamental plants such as Cornus spp., pines, and douglas fir are hosts to M. phaseolina (Farr et al., 1989; Smith and Carvil, 1977). In addition to root rots and collar rots, this fungus also causes wilt and blights on many plants. According to Barnard (1994), M. phaseolina is an opportunistic pathogen that may become severe on plants growing in soils with low fertility or under water stress with high soil temperatures, and in senescing plants (Islam et al., 2012). Although M. phaseolina has received minimal attention in ornamental species, repeated isolations of this fungus from dogwood roots and the crown region in field plantings suggest a need to evaluate its impact on flowering dogwood seedlings.

Common cultural practices used in dogwood production systems such as cover cropping with legumes, hardening-off of seedlings, root pruning, or soil fumigation have been reported to increase the infection rates by M. phaseolina (Barnard, 1994; Sarkar et al., 2014). The importance of flowering dogwood as an ornamental tree cannot be overemphasized; it has high esthetic appeal

Received for publication 13 Oct. 2017. Accepted for publication 30 Nov. 2017.

The project was partly funded by a USDA Grant 2004-02513.

${ }^{1}$ Corresponding author. E-mail: mmmbaga@tnstate. edu. in its spring bloom, summer foliage, and autumn colors (Halls and Epps, 1969; Mitchell et al., 1988; Wadl et al., 2011). Its commercial value was $\$ 30$ million in 2009 ; it is an important crop in the Tennessee state economy (USDA, 2012). Tennessee is the major producer of $C$. florida with $\approx 75 \%$ of the U.S. sales, and many rural communities depend on dogwood production for income. Because the impact of $M$. phaseolina on flowering dogwood plant health has not been reported, this study was conducted with the following objectives: 1) to evaluate pathogenicity of $M$. phaseolina isolates on C. florida seedlings and 2) to determine its effects on seedlings and potential impact on plant growth.

\section{Materials and Methods}

Confirmation of the identity of $\mathrm{M}$. phaseolina isolates from dogwood root rot. Nine fungal isolates were obtained from roots and the crown region of distressed mature plants that exhibited scotched leaves and drought-like symptoms in nursery field located at the Otis Floyd Nursery Research Center, on the landscape in McMinnville, and at the Battleground Park in Murfreesboro, TN; healthy plants were not sampled. All fungal isolates were grown in multi-extract agar (MEA, Difco; Sparks, MO) at $25 \pm 2{ }^{\circ} \mathrm{C}$ and identified using the morphological features and DNA sequence analysis. A total of three isolates were analyzed from each collection site. Standard DNA extraction techniques using Qiagen DNeasy Plant Mini Kit (Qiagen Inc, Valencia, CA) and polymerase chain reaction (PCR) procedures using universal primers internal transcribed spacer (ITS) 1 and ITS 4 followed standard protocols for the DNA sequence analysis. The samples were sent to Davis Sequencing Inc. (http://www.davissequencing.com) for DNA sequencing. A data analysis on DNA sequences was conducted using Blast search (blast.ncbi.nlm.nih.gov) and closest similarity match to partial sequences available at the Genbank database at $\geq 99 \%$ identity.

Evaluation of pathogenicity of $\mathrm{M}$. phaseolina isolates on C. florida and its potential impact on plant growth. Seeds of C. florida were surface disinfected in $2 \%$ Clorox for $2 \mathrm{~min}$, rinsed three times in sterilized water, and then vernalized for three months at $4{ }^{\circ} \mathrm{C}$ in moistened sterilized soil mix (Morton's Grow Mix \#2; Morton's Horticultural Supplies Inc., McMinnville, TN). Seedlings from vernalized seeds were selected for growth uniformity, soaked in $1 \%$ Clorox for $1 \mathrm{~min}$, and rinsed three times in sterile water. Then, they were transferred onto a sterile filter paper overlaid on water agar in large $150 \mathrm{~mm} \times 15 \mathrm{~mm}$ petri plates. A total of 15 seedlings were placed on each petri plate and the filter papers were kept moist using sterilized water. Roots were then inoculated with three isolates of M. phaseolina from the three collection sites using a replication of three petri plates per isolate and three plants per replicate. About $4 \times 10^{6}$ propagules $/ \mathrm{mL}$ made from 10 -d-old cultures grown in MEA were used as inoculum; nontreated controls were treated with MEA only. All roots were covered with a layer of sterile filter paper and kept moist using sterile water. The plates were sealed with parafilm and half of each plate-bearing roots were covered with aluminum foil to create a darken condition. The shoot part of the seedling was exposed to fluorescent light of $\approx 700 \mu \mathrm{mol} \cdot \mathrm{m}^{-2} \cdot \mathrm{s}^{-1}$ light intensity for $12 \mathrm{~h}$ (12:12 h light:darkness) in a growth chamber set at $25 \pm 2{ }^{\circ} \mathrm{C}$. Disease development was evaluated over a period of $30 \mathrm{~d}$. Three seedlings were removed from each petri plate every $5 \mathrm{~d}$ and the level of root infections was assessed. Thirty-five days after inoculation, roots were cleaned in sterile water and examined for colonization with $M$. phaseolina.

The study was repeated with minor modifications in which clear plastic lunch boxes of $15.2 \mathrm{~cm}$ (length) $\times 12.5 \mathrm{~cm}$ (width) $\times 5 \mathrm{~cm}$ (depth) were sterilized, lined with sterilized tissue papers, and used as growth chambers. Seedlings were lined on moist tissue papers and overlaid with a 150 -mm-diameter sterilized filter paper as described previously. Disease development was evaluated and root colonization with $M$. phaseolina was examined under a compound microscope. Thin root sections were stained by soaking in $0.05 \%$ aniline blue for $45 \mathrm{~min}$ and examined for fungal tissues and the presence of microsclerotia inside roots.

Evaluation of the effect of M. phaseolina on the dogwood lower stem/crown region. This study was performed in greenhouse conditions $\left(28 \pm 3{ }^{\circ} \mathrm{C}\right)$ using 35 -d-old seedlings grown in heat-sterilized soil (Morton's 
Grow Mix \#2; Morton's Horticultural Supplies Inc.). The lower part of the stem near the soil line was disinfected by wiping with $70 \%$ ethanol and blot-dried using a sterilized tissue paper before inoculation with mycelial plugs from 7-d-old colonies of M. phaseolina grown in MEA. Inoculation was carried out by making a small vertical incision on the lower stem near the soil level, cutting through the bark, cambium, and some xylem tissue using a sterilized surgical blade. The inoculum consisted of one mycelial plug of $5.0 \mathrm{~mm}$ diameter placed on the wound and then wrapped with parafilm; a plug of plain MEA was used as the control treatment. All plants were maintained in a greenhouse at $25 \pm 2{ }^{\circ} \mathrm{C}$ and $50 \%$ relative humidity; plants were arranged in a randomized complete block design with three replicates of individual plants per treatment. Expansion of the lesions was monitored as a measure of infection development. Thirty days after inoculation, the parafilm was removed and the level of infection was measured. The pathogen was re-isolated from the stem and crown region using standard sterile techniques. The study was repeated and the recovered fungal isolates were compared with the original isolates used for inoculation.

Statistical analysis. All statistical analyses were performed using SAS 9.1 (SAS Institute Inc., Cary, NC) general linear models procedure. Any post-analysis of variance (ANOVA) analyses were carried out using proc ANOVA and Fisher's least significant difference test at $P \leq 0.05$.

\section{Results and Discussions}

Confirmation of the identity of $\mathrm{M}$. phaseolina isolates from dogwood root rot. All isolates from C. florida produced dark brown colonies on MEA or potato dextrose agar (PDA) and got darker over time as described for $M$. phaseolina (Fig. 1). All cultures formed microsclerotia that were visible with the naked eye, but conidia were not observed. DNA analysis of all the three isolates performed using ITS 1 and ITS 2 universal primers produced PCR products of $575 \mathrm{bps}$ with a $\geq 99 \%$ identity to $M$. phaseolina in the GenBank database. The colony morphology and DNA sequence analysis showed that all isolates from dogwood were of M. phaseolina.

Evaluation of pathogenicity of $\mathrm{M}$. phaseolina isolates on C. florida and its potential impact on plant growth. All seedlings were free of any lesions before they were inoculated with M. phaseolina; all inoculated seedlings developed root necrotic lesions within $10 \mathrm{~d}$ and no small lateral roots were observed; the non-inoculated control plants remained disease-free and developed numerous small roots (Fig. 2). Observations of root pieces under a compound microscope showed that plants inoculated with $M$. phaseolina developed numerous microsclerotia, whereas non-inoculated seedlings did not exhibit microsclerotia fungal structures (Fig. 3). Because microsclerotia serve as resting structures and are readily formed in

A

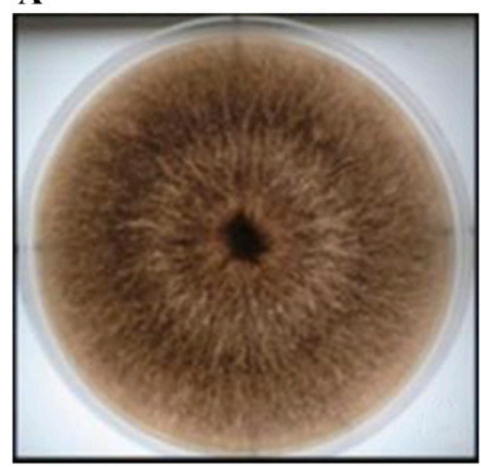

B

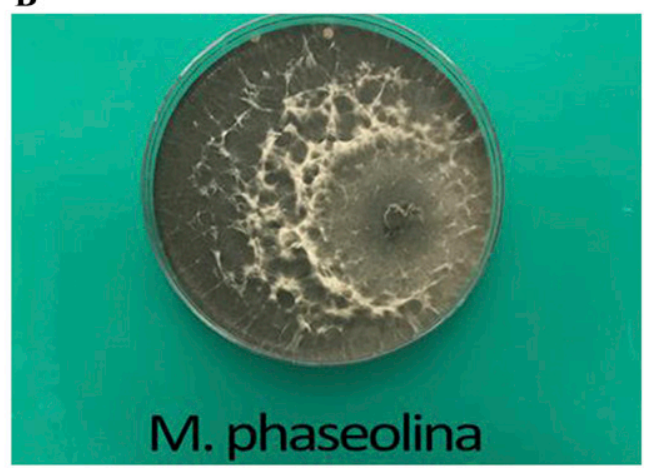

Fig. 1. Colonies of Macrophomina phaseolina isolates from Cornus florida (A) lower plate view and (B) upper plate view.

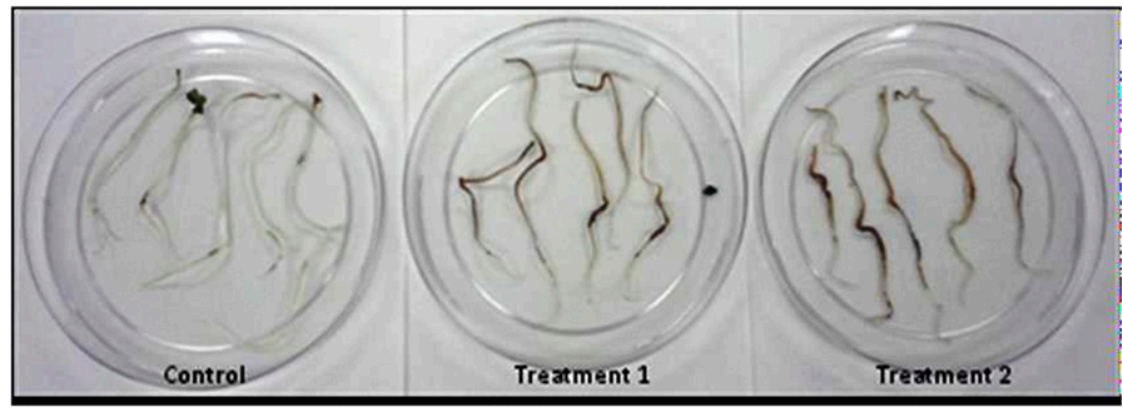

Fig. 2. Different levels of root necrotic lesions displayed on Cornus florida seedlings (treatments 1 and 2) inoculated with isolates of Macrophomina phaseolina compared with the non-inoculated control plants (control) on water agar $10 \mathrm{~d}$ after inoculation. Similar results were obtained on repeated experiments.
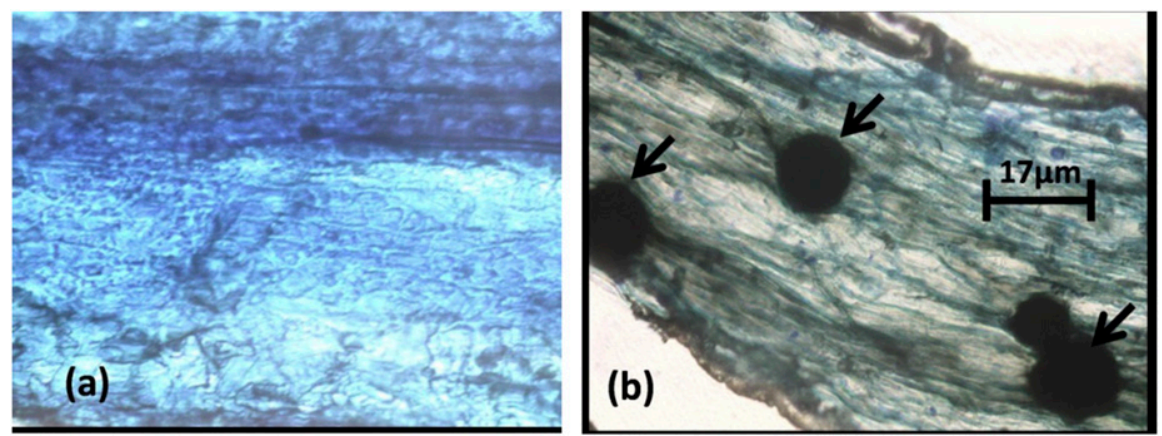

Fig. 3. Microscopic view of flowering dogwood roots showing no fungal structures on non-inoculated control (A) and microsclerotia (arrows) in roots inoculated with Macrophomina phaseolina (B).

plant tissue, infected plants may move and spread the pathogen from one place to another (Kaur et al., 2012). In addition, the development of root lesions from $M$. phaseolina is likely to affect plant growth by reducing water and nutrient uptake, especially in field plantings in soils with low fertility or under water stress with high soil temperatures (Islam et al., 2012). In our studies, neither water nor temperature was limiting, and the impact on growth was not observed. Macrophomina phaseolina has been reported to be an opportunistic pathogen that may become severe in plants growing in soils with low fertility or growing under water stress with high soil temperatures (Barnard, 1994). The M. phaseolina pathogen survives and spreads more efficiently in dry soils and in plant debris (Dingra and Sinclair, 1975; Islam et al., 2012; Papavizas, 1977; Reis et al., 2014; Short et al., 1980). Environmental conditions that favor M. phaseolina such as low moisture and high temperature are likely to occur repeatedly during field production period and in landscape plantings, thereby escalating the impact of this disease in flowering dogwood.

Evaluation of the effect of M. phaseolina on the dogwood lower stem/crown region. Stem that were inoculated with M. phaseolina mycelial plugs at the soil line developed small swellings and brownish necrotic lesions or cankers at the point of inoculation 


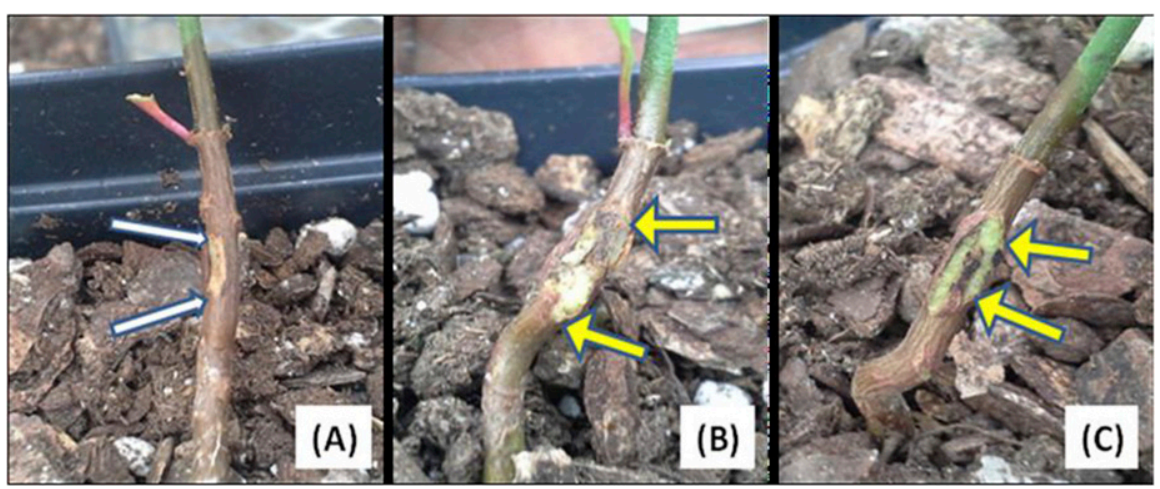

Fig. 4. Seedlings of flowering dogwood inoculated with mycelial plugs of Macrophomina phaseolina (yellow arrows); compared with control plants inoculated with plain malt extract agar plug (A, white arrows) showing symptoms of swelling and canker-like structures on repeated trials (B and $\mathbf{C})$.

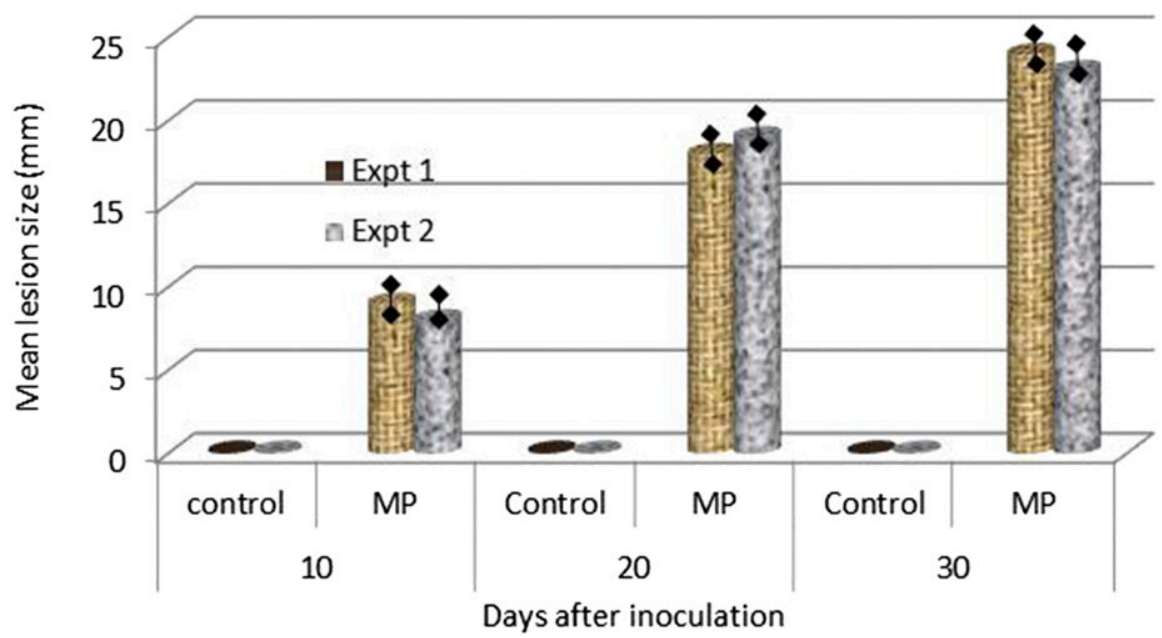

Fig. 5. Disease progression shown by mean stem lesions on flowering dogwood inoculated with 5-mmdiameter mycelial plugs of Macrophomina phaseolina (MP) at the crown region near the soil line compared with non-inoculated (control) treated with malt extract agar plugs in repeated experiments.

with the lesions spreading along the stem vertical and horizontal axis. No lesions or swellings developed on control plants that were inoculated with plain MEA mycelial plugs, and the inoculation wounds healed rapidly without developing a brown discoloration (Fig. 4). The lesions inoculated with M. phaseolina formed brownish necrotic lesions and did not heal; lesions grew significantly larger over time at $P<0.0001$ (Fig. 5). Re-isolation of the $M$. phaseolina from the necrotic lesions confirmed that the swellings and lesions on the stem (Fig. 4B and C) were caused by $M$. phaseolina. No fungus was recovered from the control plants (Fig. 4A). Infection of plant roots from stem inoculations was not evaluated, and no symptoms were observed on the leaves.

Results of this study show that $M$. phaseolina has the potential of causing cankers or stem lesions on flowering dogwood. Such lesions and cankers could possibly increase vulnerability to wood boring insects. Previous studies have reported effects of M. phaseolina on susceptible seedlings and young ornamental plants grown under stressful conditions of low moisture and high temperatures (Barnard, 1994). It has also been documented that $M$. phaseolina can be a very aggressive and promiscuous pathogen in its host range (Islam et al., 2012). Several names including $M$. phaseolina, Rhizoctonia bataticola, and Botryodiplodia phaseoli have been used in the literature to identify this fungus (Barnard and Gilly, 1986); different strains or isolates of $M$. phaseolina have also displayed genetic variability and diversity (Salahlou et al., 2016). However, genetic variability was not addressed in this study and all three isolates evaluated produced similar results. This study shows that $M$. phaseolina isolates from flowering dogwood established necrotic lesions in roots and stem of $C$. florida seedlings even when moisture and temperature were not limiting. This is the first report of canker-like lesions being produced in C. florida by $M$. phaseolina. Dogwood canker is an economically important problem in dogwood production and its causal agent is not well understood; more investigations are needed to determine the possible role of $M$. phaseolina in the development of dogwood canker.

\section{Literature Cited}

Barnard, E.L. 1994. Nursery-to-field carry over potential and post-outplant impact of Macrophomina phaseolina on loblolly pine on a cutover site in north central Florida. Tree Planters' Notes 45:68-71.

Barnard, E.L. and S.P. Gilly. 1986. Charcoal root rot of pines. Div. Plant Ind. FDACS. Plant Pathol. Circ. 290. 4 p.

Dingra, O.D. and J.B. Sinclair. 1975. Survival of Macrophomina phaseolina sclerotia in soil: Effects of soil moisture, carbon:nitrogen ratios, carbon sources, and nitrogen concentrations. Phytopathology 65:236-240.

Farr, D.F., G.F. Bills, G.P. Chamuris, and A.Y. Rossman. 1989. Fungi on plants and plant products in the United States. APS Press, St. Paul, MN.

Halls, L.K. and E.A. Epps. 1969. Browse quality influenced by tree overstory in the south. J. Wildl. Mgt. 33:1028-1031.

Islam, M.S., M.S. Haque, M.M. Islam, E.M. Emdad, A. Halim, Q.M. Hossen, M.Z. Hossain, B. Ahmed, S. Rahim, M.S. Rahman, M.M. Alam, S. Hou, X. Wan, J.A. Saito, and M. Alam. 2012. Tools to kill: Genome of one of the most destructive plant pathogenic fungi Macrophomina phaseolina. BMC Genomics 13:493508.

Kaur, S., G.S. Dhillon, S.K. Brar, and V.B. Chauhan. 2012. Carbohydrate degrading enzyme production by plant pathogenic mycelia and microsclerotia isolates of Macrophomina phaseolina through koji fermentation. Ind. Crops Prod. 36:140-148

Mitchell, W.A, P.A. Gibbs, and C.O. Martin. 1988. Flowering Dogwood (Cornus florida). Section 7.5. 9 US Army Corps of Engineers Wildlife Resources Management Manual. Technical Report EL-88-9. Vicksburg, Mississippi: U.S. Army Engineer Waterways Experiment Station, MS $25 \mathrm{pg}$.

Papavizas, G.C. 1977. Some factors affecting survival of sclerotia of Macrophomina phaseolina in soil. Soil Biol. Biochem. 9:337-341.

Reis, E.M., C. Boaretto, and A.L.D. Daneli. 2014. Macrophomina phaseolina: Density and longevity of microsclerotia in soybean root tissues and free on the soil, and competitive saprophytic ability. Summa Phytopathol. 40:128133.

Salahlou, R., N. Safaie, and M. Shams-Bakhsh. 2016. Genetic diversity of Macrophomina phaseolina populations, the causal agent of sesame charcoal rot using inter-simple sequence repeat markers. J. Agr. Sci. Technol. 18:277-287.

Sarkar, T.S., P. Biswas, S.K. Ghosh, and S. Ghosh. 2014. Nitric oxide production by necrotrophic pathogen Macrophomina phaseolina and the host plant in charcoal rot disease of jute: Complexity of the interplay between necrotroph-host plant interactions. PLoS One 9:E107348

Short, G.E., T.D. Wyllie, and P.R. Bristow. 1980. Survival of Macrophomina phaseolina in soil and in residue of soybean. Ecol. Epidemiol. 70:13-17.

Smith, G.S. and Carvil, O.N. 1977. Field screening of commercial and experimental soybean cultivars for their reaction to Macrophomina phaseolina. Plant Dis. 81:363-368.

U.S. Department of Agriculture (USDA). 2012. Census of agriculture. USDA, Washington, DC.

Wadl, P.A., A.M. Saxton, X. Wang, V.R. Plantalone, T.A. Rinehart, and R.N. Trigiano. 2011. Quantitative trait loci associated with red foliage in Cornus florida L. Mol. Breed. 27:409416. 